\title{
Experimental Testing of an Indigenous Solar Driven Desiccant Cooling System for Local Conditions of Pakistan
}

\author{
Shujaa Arshad ${ }^{1}$, Muhammad Umair ${ }^{*}$, Rana Shahzad Noor ${ }^{1}$, Chaudhry Arslan ${ }^{2}$, Arslan Afzal $^{1}$ and Zafar \\ Islam $^{3}$
}

${ }^{1}$ Faculty of Agricultural Engineering and Technology, PMAS-Arid Agriculture University Rawalpindi, Pakistan; ${ }^{2}$ Faculty of Agricultural Engineering and Technology, University of Agriculture Faisalabad, Pakistan; ${ }^{3}$ National Agricultural Research Center, Islamabad, Pakistan.

\begin{abstract}
Demand for space cooling is increasing with a rapidly growing population. Cooling is not only required for comfort life but also needed to store food and medicine. Cooling needs are fulfilled with conventional cooling systems that use huge electric power and also these systems are not environment friendly. Therefore, it is needed to use alternate energy sources for cooling systems with environmentally friendly technologies. In this research, a small scale solar-driven desiccant cooling system was developed with 3 feet length, 2 feet width and 2 feet height and tested for local environmental conditions of Pakistan. Pakistan has blessed with an abundance of solar energy in most parts of the country and desiccant cooling technology in an environment as well as user-friendly technology. The objective of this study was to test the developed system for local conditions of Pakistan so that this technology can be promoted to be used in agriculture for control sheds/greenhouses for cooling demands using solar energy. The system was developed using local materials and was installed to cool a small room. Parameters such as temperature and humidity were recorded for room and ambient environment. The results showed that prototype help to keep the room temperature up to $4{ }^{\circ} \mathrm{C}$ to $5^{\circ} \mathrm{C}$ lower than the ambient temperature while using the only solar energy through PV panel. The use of solar energy with new technologies in Pakistan is not yet adopted on large scale. This research will promote the researcher and user to adopt such technologies as Pakistan has great potential to harvest solar energy.

Received | January 07, 2020; Accepted | March 15, 2021; Published | June 12, 2021

*Correspondence | Muhammad Umair, Faculty of Agricultural Engineering and Technology, PMAS-Arid Agriculture University Rawalpindi, Pakistan; Email: umairkpr@uaar.edu.pk

Citation | Arshad, S., M. Umair, R.S. Noor, C. Arslan, A. Afzal and Z. Islam. 2021. Experimental testing of an indigenous solar driven desiccant cooling system for local conditions of Pakistan. Pakistan Journal of Agricultural Research, 34(3): 400-404.

DOI | https://dx.doi.org/10.17582/journal.pjar/2021/34.3.400.404

Keywords | Adsorption cooling, Desiccant wheel, Dehumidification, Solar cooling
\end{abstract}

\section{Introduction}

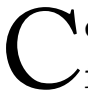
ooling demand is increasing day by day not only for industry and domestic purposes but also for the agriculture sector. Mostly conventional technologies are used for cooling purposes. Conventional air conditioning systems work on a vapour compression cycle that involves high consumption of energy and emission of harmful gases (Parmar and Hindoliya, 2011). Therefore, it is needed to use alternate technologies for cooling purposes using renewable energy resources that are environmentally friendly and cost-effective. Adsorption, absorption and desiccant cooling systems are some examples of alternative of conventional cooling technologies. If these technologies are driven with renewable 
energy resources such as solar energy, then it will be a sustainable way to achieve cooling. with minimum effect on the environment (Mujahid et al., 2015).

Pakistan is one of those countries who are facing severe energy crises and environmental issues. Fortunately, Pakistan is located in a region with plenty of sunny days (20-25 per month) and sunny hours (250-300 per month as shown in Figure 1. Therefore, there is great potential to harvest solar energy and effectively use for various purposes including to achieve or drive cooling systems. Many technologies can be used for space cooling using solar energy as an alternative to a conventional system. These technologies include adsorption, absorption and desiccant cooling. Desiccant cooling has an advantage over other technologies because it can be driven by low-grade energy source and it works at atmospheric pressure, therefore, it does not require a sophisticated system to produce a vacuum as needed in case of the adsorption system (Ge et al., 2014). Development of the desiccant system started by Shelpuk and Hooker (1979). Solar driven desiccant cooling system with rotational dehumidification wheel is a great option for air conditioning (Sultan et al., 2018). It allows maintaining continuous working cycle with a low temperature of $50{ }^{\circ} \mathrm{C}$ to $80^{\circ} \mathrm{C}$ (Niaz et al., 2018). The desiccant cooling system tends to lower energy consumption 5\% for heating and 30\% for conditioner space (Shelpuk and Hooker, 1979).

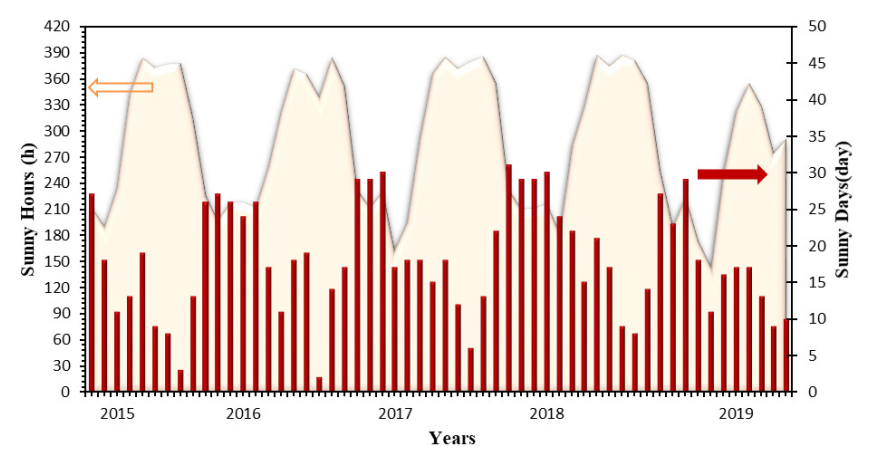

Figure 1: Last 5 years data of sunny days and sunny hours of Rawalpindi, Pakistan (Weather Atlas, 2019).

Desiccant is a hygroscopic material that works on the pressure difference. Moisture from air adsorbs on the upper surface of the desiccant material because of high pressure. This moisture releases back to the atmosphere due to the application of hot and highpressure air. Because of its potential advantages and applications desiccant cooling can be a promising technology in Pakistan to cope with cooing demand in various sectors. There are limited studies on the use of desiccant cooling in Pakistan (Khalid et al., 2009; Ali et al., 2015; Farooq et al., 2020; Kashif et al., 2020). Mostly these studies describe simulation work or solar-assisted desiccant system. In this study, a small scale solar-driven desiccant cooling system was developed. The objective was to test the system for local conditions of Pakistan. This study will be helpful for promotion and adaptation of such cost-effective and friendly technologies in Pakistan to cope with the cooling demands by using abundantly available solar energy.

\section{Materials and Methods}

\section{System description and specifications}

The proposed system is configured into four subsystems that are solid desiccant dehumidification chamber, evaporative cooling, heat exchanger/regeneration chamber and PV panel. There are two compartments one is dehumidification and the other is a regeneration compartment. Desiccant dehumidification system consists of a desiccant wheel filled with $2.5 \mathrm{~kg}$ of silica gel. The desiccant wheel is placed between dehumidification and regenerative compartment to remove the adsorbed moisture. In evaporative cooling, water sprinkles continuously on the cooling pad through a water pump. In regeneration compartment, hot water circulates in copper pipes heat exchanger. $\mathrm{PV}$ panel is used to supply the required electricity to operate the blowers, fans and pumps. The details and specifications of different components used in the proposed system are given in Tables 1 and 2.

\section{Working principle}

Ambient air enters the desiccant system at point 1 as shown in Figure 2 and passes through the desiccant wheel. The moisture from the air is adsorbed, the humidity of air decreases while its temperature increases (point 2). After that this hot and low humid air is passed through the evaporative cooling system and gets cool (point 3). This cool air is then supplied to the room. In the regeneration compartment, ambient air enters (point 4) and passes through the heat exchanger and get heated (point 5). When this hot air passes through the desiccant wheel it removes moisture from desiccant material. The air is circulated in both compartments with the help of blower and fans. 
Table 1: Specifications of the item used in the desiccant system.

$\begin{array}{lll}\text { Items } & \text { Quantity } & \text { Specifications } \\ \text { The dimension of the system } & 1 & 0.91 \mathrm{~m}(3 \mathrm{ft}) \times 0.6 \mathrm{~m}(2 \mathrm{ft}) \times 0.6 \mathrm{~m}(2 \mathrm{ft})(\mathrm{L} \times \mathrm{W} \times \mathrm{H}) \\ \text { Fan } & 3 & \text { Discharge }=4361 \mathrm{l} / \mathrm{min}(154 \mathrm{CFM})(\mathrm{each}) \\ \text { Blower } & 2 & \mathrm{~V}=12 \mathrm{v}, \mathrm{I}=1.3 \mathrm{~A} \\ \text { Submersible pump } & 2 & \text { Discharge }=5 \mathrm{~L} / \mathrm{min} . \text { Max allowable head }=5 \mathrm{~m} \\ \text { Desiccant wheel motor } & 1 & \mathrm{I}=12 \mathrm{~V}, \omega=40 \mathrm{rpm} \\ \text { Sensor } & 4 & (\text { Tmperature+humidity }) \\ \text { Silica gel } & 1 & 2.5 \mathrm{~kg} \\ \text { Heat exchanger } & 2 & \text { copper pipes }\end{array}$

Table 2: Power requirement of the system.

$\begin{array}{llll}\text { Items } & \text { Quantity } & \begin{array}{l}\text { Power requirement } \\ \mathbf{P}(\mathbf{W})=\text { Volt }(\mathbf{V}) \times \text { Current (Ampere) }\end{array} & \begin{array}{l}\text { Total power require } \\ \text { (Watt) }\end{array} \\ \text { Fan } & 3 & 15.6=12 \times 1.3 & 46.8 \\ \text { Blower } & 2 & 15.6=12 \times 1.3 & 31.2 \\ \text { Submersible pump } & 2 & 18=12 \times 1.5 & 36 \\ \text { Desiccant wheel motor } & 1 & 36=12 \times 3 & 36 \\ \text { Total power required } & & & 150 \\ \text { PV panel used } & & & 170\end{array}$

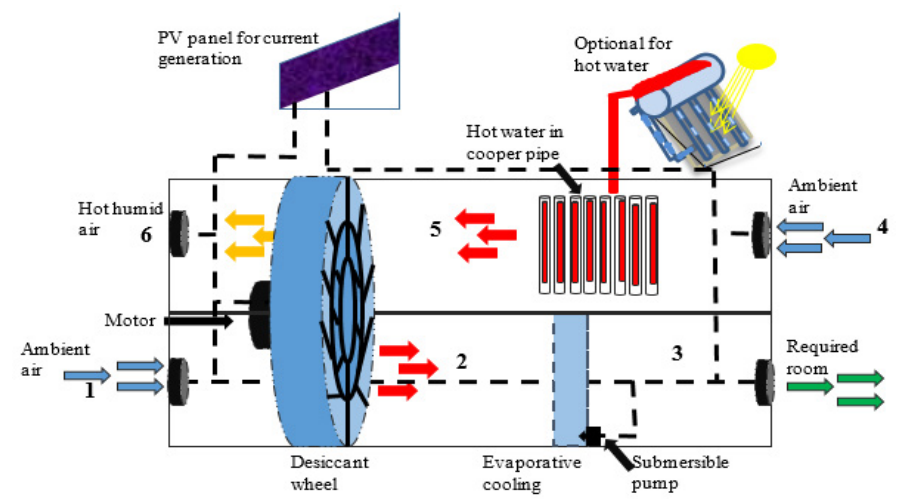

Figure 2: Schematic diagram of the proposed solar-porvered desiccant wheel cooling system.

\section{Experimental setup}

The system was installed in the room at the Faculty of Agricultural Engineering and Technology, PMAS Arid Agriculture University Rawalpindi. The room has a size of $3.6 \mathrm{~m}(12 \mathrm{ft}) \times 3 \mathrm{~m}(10 \mathrm{ft}) \times 3 \mathrm{~m}(10$ $\mathrm{ft})(\mathrm{L} \times \mathrm{W} \times \mathrm{H})$. Installation of the desiccant system is shown in Figure 3. Sensors (digital sensor measuring temperature and humidity at same time) were placed on the different locations of the system and room to measure temperature and humidity at the inlet of system, after the desiccant wheel, after the evaporative cooling unit and in the room to find the change in humidity and temperature. PV panel was installed on the rooftop to supply the required power for the system.

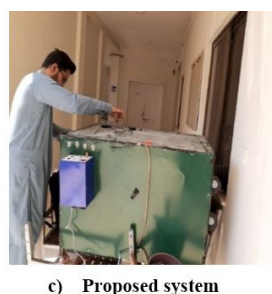

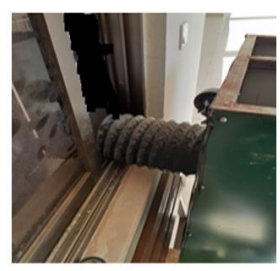

b) Inlet to room

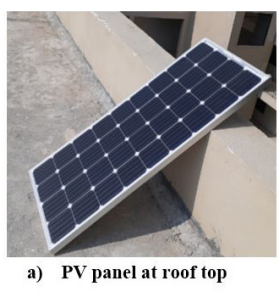

Figure 3: Installation of the proposed system and components.

\section{Results and Discussion}

After installing the desiccant system, data was recorded after $5 \mathrm{~min}$ interval for the whole day from 9:30 am to 5:00 pm on a sunny day. Figure 4 shows the change in temperature of ambient air (red line with circular marker), after desiccant wheel (black line with cross maker), outlet from the system/inlet to the room (green line with square marker) and at the centre of the room (blue line with filled circular marker).

It can be noted that room temperature is lower near the system from where the cool air is coming while the temperature at the centre of the room remains near 30 ${ }^{\circ} \mathrm{C}$ even in the middle of the day when the ambient temperature was $37{ }^{\circ} \mathrm{C}$. The room inlet temperature is lowered in starting hours of the day and increases after that but remains lower than ambient and room central temperature. On average, the system reduces 
the room temperature $4^{\circ} \mathrm{C}$ to $5^{\circ} \mathrm{C}$ lower than ambient temperature using only solar energy as a power source.

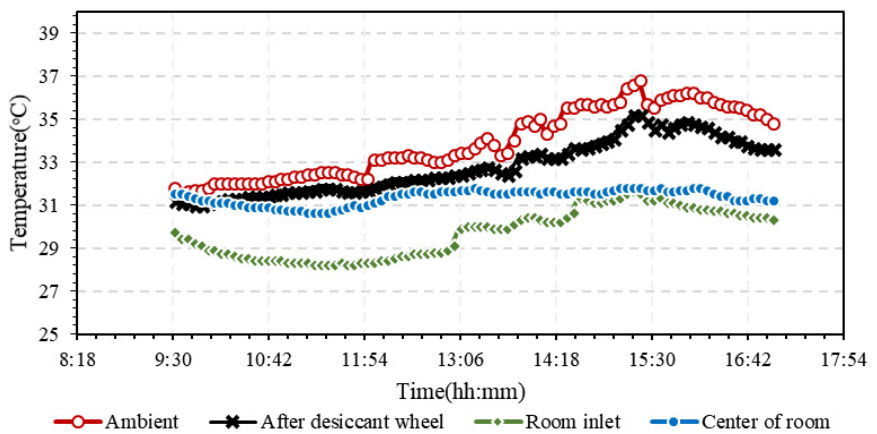

Figure 4: Temperature variation during system operation.

Figure 5 shows the change in humidity at the same locations described for Figure 4. It can be noted that the humidity of the room remains higher both at the inlet and the centre of the room compared to the ambient humidity. This is because of the water cooling pad used after the desiccant wheel.

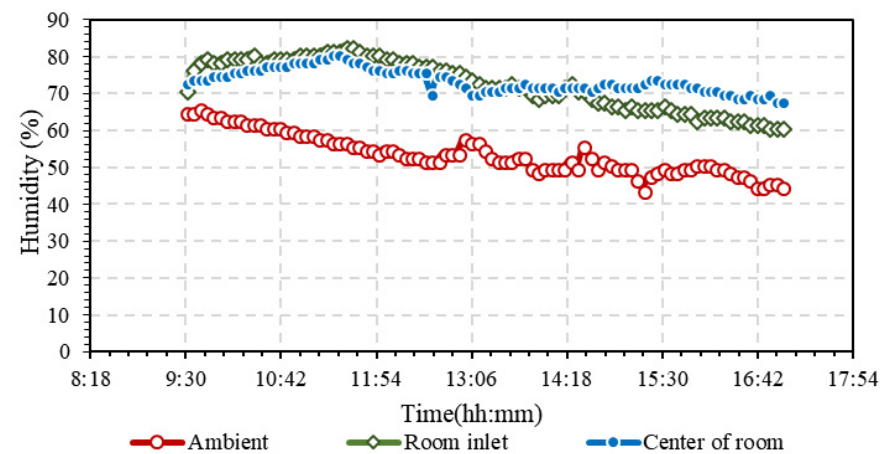

Figure 5: Humidity variation during system operation.

The system performance was estimated for yearround operation for Rawalpindi area by projecting the temperature that can be maintained by the proposed system. The system temperature was estimated by subtracting $4{ }^{\circ} \mathrm{C}$ from the maximum temperature as shown in Figure 6. Here red bars show the maximum temperature of the month, green bars show the minimum temperature and blue bars are indicating the temperature that can be lower by the proposed desiccant cooling system. It can be seen from the results that in summer months the temperature can be lowered to $20{ }^{\circ} \mathrm{C}$ to $24{ }^{\circ} \mathrm{C}$ against the ambient temperature of $33{ }^{\circ} \mathrm{C}$ to $39{ }^{\circ} \mathrm{C}$, resprectively. This temperature range is quite suitable not only for domestic confort but also for controlled greenhouses like hydroponic for optimum plant growth. Therefore, the proposed system has great potential and scope in Pakistan that will be helpful to fulfill the cooling demand not only for domestic but also for agriculture sector in summer sessions using solar energy.

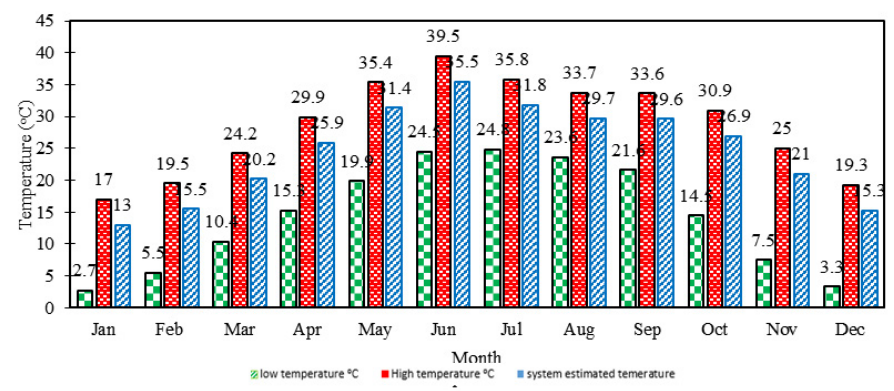

Figure 6: Yearly system estimated temperature against recorded data (Weather Atlas, 2019).

\section{Conclusions and Recommendations}

This research paper is about the desiccant cooling system a possible substitute for conventional technology. Due to climate changes issue, it is not a wise decision to rely on non-renewable energy resources that are not environment friendly and also depleting rapidly. We must go to sustainable technologies and renewable resources. The use of solar energy with new technologies in Pakistan is not yet adopted. In this research a small scale solar-driven desiccant cooling system for was developed. The objective was to test the performance for the local conditions of Pakistan. The prototype was tested at Rawalpindi, Pakistan on a sunny day. The results showed that the system can lower the room temperature $4-5{ }^{\circ} \mathrm{C}$ lower than ambient temperature using only solar energy as a power source. This proposed cooling system is cost-effective, user friendly can be used as an alternative to conventional technology. This research will promote the researcher and users to adopt such technologies as $\mathrm{Pa}-$ kistan has great potential to harvest solar energy.

\section{Novelty Statement}

An indigenous solar based desiccant cooler is developed and tested for Pakistan climate. The results showed that the system can lower the room temperature $4-5{ }^{\circ} \mathrm{C}$ lower than ambient temperature using only solar energy as a power source.

\section{Author's Contribution}

Shujaa Arshad: Conceived the idea, development of the model, data collection.

Muhammad Umair: Conceived the idea, technical inputs and guidance, Overall management of article.

Rana Shahzad Noor: Literature review, technical 
guidance.

Chaudhry Arslan: Technical and article guidance.

Arslan Afzal: Helped in development and manufacturing.

Zafar Islam: Data managing and Introduction.

\section{Conflict of interest}

The authors have declared no conflict of interest.

\section{References}

Ali, M., V. Vukovic, N.A. Sheikh, H.M. Ali and M.H. Sahir. 2015. Enhancement and integration of desiccant evaporative cooling system model calibrated and validated under transient operating conditions. Appl. Therm. Eng., 75:1093-1105.https://doi.org/10.1016/j. applthermaleng.2014.10.064

Farooq, A.S., A.W. Badar, M.B. Sajid, M. Fatima, A. Zahra and M.S. Siddiqui. 2020. Dynamic simulation and parametric analysis of solar assisted desiccant cooling system with three configuration schemes. Sol. Energy, 197: 22-37. https://doi.org/10.1016/j.solener.2019.12.076

Ge, T.S., Y.J. Dai and R.Z. Wang. 2014. Review on solar powered rotary desiccant wheel cooling system. Renew. Sustain. Energy Rev., 39: 476497.https://doi.org/10.1016/j.rser.2014.07.121

Kashif, A., M. Ali, N.A. Sheikh, V. Vukovic and M. Shehryar. 2020. Experimental analysis of a solar assisted desiccant-based space heating and humidification system for cold and dry climates. Appl. Therm. Eng., 175: 115371. https://doi. org/10.1016/j.applthermaleng.2020.115371
Khalid, A., M. Mahmood, M. Asif and T. Muneer. 2009. Solar assisted, pre-cooled hybrid desiccant cooling system for Pakistan. Renew. Energy, 34: 151-157.https://doi.org/10.1016/j. renene.2008.02.031

Mujahid, R.M., P. Gandhidasan, S. Rehman and L.M. Al-Hadhrami. 2015. A review on desiccant based evaporative cooling systems. Renew. Sustain. Energy Rev., 45: 145-159. https://doi.org/10.1016/j.rser.2015.01.051

Niaz, H., M. Sultan, T. Miyazaki and Z.M. Khan. 2018. Study on desiccant air-conditioning system for livestock application in Pakistan. ICECE 2018, $2^{\text {nd }}$ Int. Conf. Energy Conserv. Effic. Proc.,pp.19-22. https://doi.org/10.1109/ ECE.2018.8554983

Parmar, H. and D. Hindoliya. 2011. Desiccant cooling system for thermal comfort: A review. Int. J. Eng. Sci., 3: 4218-4227.

Shelpuk, B.C. and D.W. Hooker. 1979. Development programmes in solar desiccant cooling for residential buildings. Int. J. Refrig., 2: 173-179. https://doi.org/10.1016/01407007(79)90142-7

Sultan, M., T. Miyazaki and S. Koyama. 2018. Optimization of adsorption isotherm types for desiccant air-conditioning applications. Renew. Energy, 121: 441-450. https://doi. org/10.1016/j.renene.2018.01.045

Weather Atlas, 2019. Rawalpindi, Pakistan. Detailed climate information and monthly weather forecast. Available at https://www. weather-atlas.com/en/pakistan/rawalpindiclimate. Accessed 10 Oct. 2019. 